\title{
Tobacco chewing and risk of gastric cancer: a case- control study in Yemen
}

\author{
F.A. Al-qadasi ${ }^{1}$, S.A. Shah ${ }^{1,2}$, H.F. Ghazi ${ }^{3}$
}

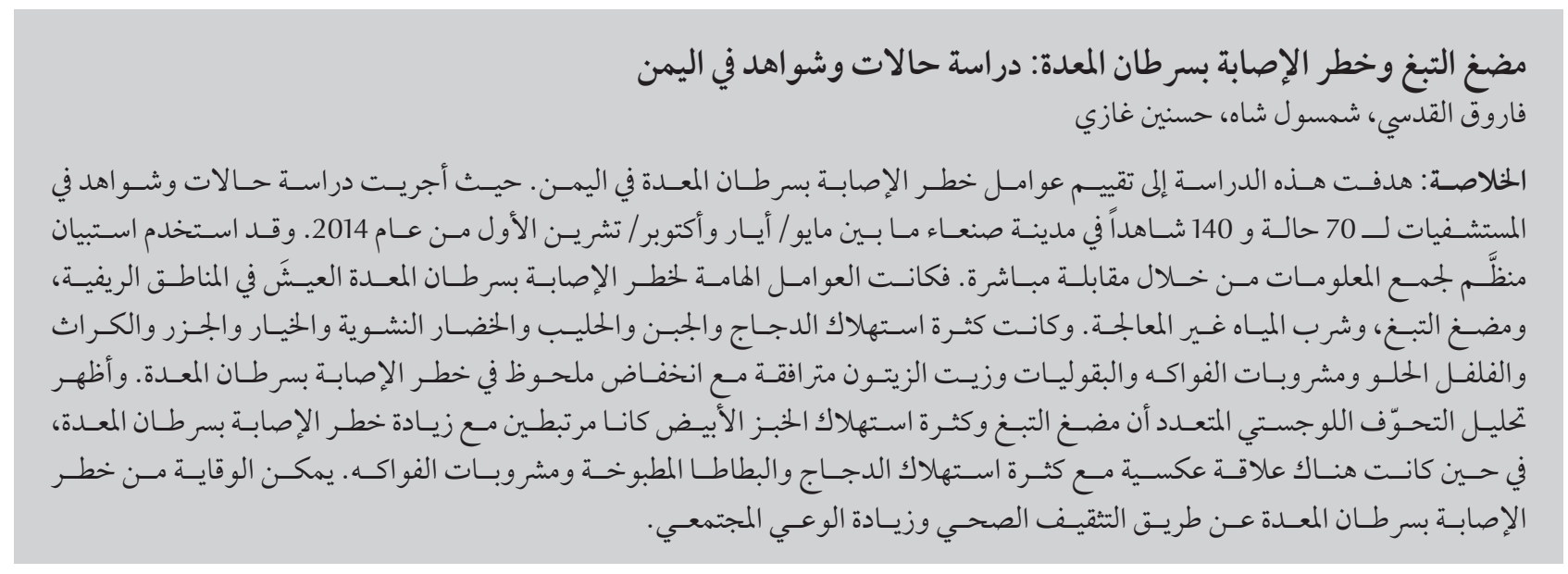

ABSTRACT This study aimed to assess the risk factors for gastric cancer in Yemen. A hospital-based case-control study of 70 cases and 140 controls was carried out in Sana'a city between May and October 2014. A structured questionnaire was used to collect information through direct interview. Living in rural areas, tobacco chewing and drinking untreated water were significant risk factors for gastric cancer. Frequent consumption of chicken, cheese, milk, starchy vegetables, cucumber, carrots, leeks, sweet pepper, fruit drinks, legumes and olive oil were associated significantly with decreased risk of gastric cancer. Multiple logistic regression analysis showed that chewing tobacco and frequent consumption of white bread were associated with increased risk of gastric cancer, whereas frequent consumption of chicken, cooked potatoes and fruit drinks had an inverse association. Risk of gastric cancer can be prevented by health education and increasing community awareness.

\section{Tabac à chiquer et risque de cancer de l'estomac : étude cas-témoin au Yémen}

RÉSUMÉ La présente étude avait pour objectif d'évaluer les facteurs de risque du cancer de l'estomac au Yémen. Une étude cas-témoin en milieu hospitalier impliquant 70 cas et 140 témoins a été menée dans la ville de Sanaa entre mai et octobre 2014. Un questionnaire structuré a été utilisé pour collecter des informations au cours d'entretiens directs. La résidence en zone rurale, la consommation de tabac à chiquer et d'eau de boisson non traitée constituaient des facteurs de risque significatifs pour le cancer de l'estomac. Une consommation fréquente de poulet, de fromage, de lait, de légumes riches en amidon, de concombres, de carottes, de poireaux, de poivrons, de boissons fruitées, de légumes et d’huile d'olive était fortement associée à une diminution du risque de cancer de l'estomac. L'analyse de régression logistique multiple a montré que le tabac à chiquer et une consommation fréquente de pain blanc étaient associés à une augmentation du risque de cancer de l'estomac, tandis que la consommation fréquente de poulet, de pommes de terre cuites et de boissons fruitées avait une association inverse. Il est possible de prévenir le risque de cancer de l'estomac grâce à une éducation en santé et à la sensibilisation de la communauté.

'Department of Community Health, Faculty of Medicine, University of Science and Technology, Sana'a, Yemen (Correspondence to: S.A. Shah: drsham@ppukm.ukm.edu.my); ${ }^{2}$ Medical Molecular Biological Institute, Universiti Kebangsaan Malaysia, Kuala Lumpur, Malaysia. ${ }^{3}$ Community Medicine Unit, International Medical School, Management and Science University, Shah Alam, Selangor, Malaysia.

Received: 22/09/15; accepted: 31/08/16 


\section{Introduction}

Gastric cancer is a major contributor to mortality and morbidity worldwide. GLOBOCAN 2012 reported 952000 new cases of gastric cancer in 2012 (6.8\% of the total number of cancer cases), making it the fourth most common malignancy in men and the fifth most common in women worldwide. More than $70 \%$ of cases occurred in developing countries, and about half of the global total occurred in East Asia (mainly in China). Gastric cancer was the third leading cause of cancer death in both sexes worldwide in 2012 (723 000 deaths, $8.8 \%$ of the total) (1). Gastric cancer shows regional variations because of differences in dietary patterns, and the prevalence of Helicobacter pylori infection (2). There has been a steady decline in recent years in most developed countries and in countries with high incidence rates in Asia (Japan, China and Korea), Latin America (Colombia and Ecuador) and Europe (Ukraine) (3).

Gastric cancer is a multifactorial disease. A positive family history of gastric cancer has been associated with a twoto threefold increased risk of the disease, which suggests a genetic basis (4). Diet is considered to play an important role in the occurrence of gastric cancer. Salty food and smoked or marinated food deficient in vitamins and antioxidants significantly increases the probability of gastric cancer (4-6). Vegetables, especially nonstarchy and allium vegetables, fruits and pulses (legumes) decrease the risk of gastric cancer (5), and green tea also reduces the risk. Antioxidants such as vitamins $\mathrm{C}$ and $\mathrm{E}, \beta$-carotene, or micronutrients such as zinc or magnesium have been shown to have protective effects against gastric cancer (7).

The National Cancer Registry in Yemen is not comprehensive and there are no reliable data available. According to GLOBOCAN 2012, the incidence of gastric cancer in Yemen was 422 new cases per 100000 (3.7\% of the total number of cancer cases), making it the seventh most common malignancy in both sexes. In men, it was the sixth most common malignancy with 279 new cases per 100000 (5.2\% of the total) but in women, it was the 11th most common malignancy with 143 new cases per 100000 (2.4\% of the total) (1). A study done in Hadramout, Yemen, in 2006, showed that gastric cancer was the second most common type of gastrointestinal cancer after colorectal cancer. It was the sixth most common type of all cancers among men and the ninth among women (8). In Yemeni society, the habit of chewing khat (Catha edulis) is highly prevalent among adults of both sexes and most of them start chewing in childhood. It is estimated that up to $90 \%$ of adult men, $73 \%$ of women, and $15-20 \%$ of children under the age of 12 years in Yemen chew khat (9). There are three main alkaloids present in khat leaves: cathinone, norpseudoephedrine (cathine), and norephedrine (10). Khat is exposed to carcinogenic substances, such as fertilizers, herbicides and pesticides, that are widely used by farmers in Yemen to ensure that they have > 1 harvest a year (11). Khat chewing is concurrently used with tobacco smoking, which may increase the burden of cancer.

No studies have focused on risk factors of gastric cancer in Yemen. The Yemeni people have particular habits such as chewing khat and tobacco, which is also called shamma (a type of tobacco that is put between the lip and tongue or above the tongue). Therefore, it is pertinent that we explore the association of khat and tobacco with gastric cancer. This study was conducted to assess the risk factors for gastric cancer in Yemen, especially to identify the association between gastric cancer and khat and tobacco chewing and certain dietary factors.

\section{Methods}

\section{Study design and sampling}

This study was a hospital-based casecontrol study that was carried out in Sana'a City. The cases were all patients who had histologically confirmed gastric cancer, collected from the National Oncology Centre in Sana'a City, which is a specialized centre that receives referrals from hospitals for chemotherapy and radiotherapy. The controls were collected from the two major hospitals in Sana'a City (Al-Thawra and AlJomhori) from where the cases were referred. The controls were selected randomly from outpatient clinics (5.3\%) or inpatient departments (medical $57.6 \%$, surgical $31.1 \%$ and gynaecological 6.1\%) during the study period. The controls were free from any malignant tumours or digestive tract disorders, and matched to cases for age ( \pm 5 years) and gender. The case to control ratio was 1:2. Patients with other concurrent types of cancer were excluded.

\section{Data collection}

The data were collected between May and October 2014. A structured questionnaire was used to collect information through direct interview about the risk factors for gastric cancer from cases and controls. The questionnaire included: general characteristics (age, sex, marital status, occupation, income, house ownership, residence and educational level); special habits (smoking and khat and tobacco chewing); past history of peptic ulcer or comorbidity; family history of gastric cancer or other malignant tumours; source of drinking water; and history of consumption of 41 different types of grains, fruits and vegetables. Dietary history was collected by validated questionnaire taken from Cancer Council, Australia (12) and modified for the diet in Yemen. Cronbach's $\alpha$ for the modified questionnaire was 0.79 . 


\section{Operational definition of variables}

The dependent variable was gastric cancer that was confirmed histologically by biopsy at any stage. The independent variables were sociodemographic factors such as education status, occupation, house ownership, history of smoking, tobacco and khat chewing, family history of gastric cancer or other cancers, and source of drinking water (treated and untreated water). Diet was categorized into three classes according to consumption frequency (never, infrequent; once monthly, 2 or 3 times per month, 1-6 times per year, 7-11 times per year; and frequent; once daily, $\geq 2$ times daily, 1 or 2 times per week, 3 or 4 times per week, 5 or 6 times per week).

\section{Data analysis}

SPSS version 21 was used to analyse the data. Frequency (\%) was used to describe the qualitative variables, and mean and standard deviation (SD) were used to describe the quantitative variables. Odds ratios (OR) and 95\% confidence intervals (CIs) were calculated to measure the risk. The $\chi^{2}$ and Fisher's exact tests were used to show the significance of association between cases and controls and the risk factors for gastric cancer at a significance level of 0.05. Multiple logistic regression was used to calculate adjusted odds ratio and the corresponding 95\% CI for gastric cancer in relation to exposures of interest.

\section{Ethical consideration}

The study was reviewed and approved bytheMedicalResearchEthicsCommittee, Department of Scientific Research, University of Science and Technology, Sana'a City, Yemen (approval No 03/2014).

\section{Results}

The demographic features of the cases and controls are shown in Table 1. There were 70 cases and 140 controls, with a mean (SD) age of 57.9 (12.79) and $57.6(11.80)$ years, respectively. Men constituted $67.1 \%$ of the gastric cancer patients and $72.1 \%$ of the controls. Cases were slightly less educated compared with the controls, but there were no significant associations between cases and

\begin{tabular}{|c|c|c|c|c|c|c|c|c|c|c|}
\hline \multirow[t]{2}{*}{ Variable } & \multicolumn{3}{|c|}{$\begin{array}{c}\text { Cases } \\
(n=70)\end{array}$} & \multicolumn{3}{|c|}{$\begin{array}{l}\text { Controls } \\
(n=140)\end{array}$} & \multirow[t]{2}{*}{$P$ value } & \multirow[t]{2}{*}{ OR } & \multicolumn{2}{|c|}{$95 \% \mathrm{Cl}$} \\
\hline & Mean (SD) & Freq & $\%$ & Mean (SD) & Freq & $\%$ & & & Lower & Upper \\
\hline Age (yr) & $57.9(12.79)$ & & & $57.6(11.80)$ & & & & & & \\
\hline$<45$ & & 8 & $11.4 \%$ & & 14 & $10.0 \%$ & 0.729 & Ref & & \\
\hline $45-64$ & & 38 & $54.3 \%$ & & 84 & $60.0 \%$ & & 0.79 & 0.31 & 2.05 \\
\hline$\geq 65$ & & 24 & $34.3 \%$ & & 42 & $30.0 \%$ & & 1.00 & 0.37 & 2.73 \\
\hline Sex & & & & & & & 0.521 & 0.79 & 0.42 & 1.47 \\
\hline Male & & 47 & $67.1 \%$ & & 101 & $72.1 \%$ & & & & \\
\hline Female & & 23 & $32.9 \%$ & & 39 & $27.9 \%$ & & & & \\
\hline Education status & & & & & & & 0.880 & 1.07 & 0.44 & 2.62 \\
\hline Lower education & & 62 & $88.6 \%$ & & 123 & $87.9 \%$ & & & & \\
\hline Higher education & & 8 & $11.4 \%$ & & 17 & $12.1 \%$ & & & & \\
\hline Marital status & & & & & & & 0.755 & 1.16 & 0.45 & 2.97 \\
\hline Married & & 63 & $90.0 \%$ & & 124 & $88.6 \%$ & & & & \\
\hline Unmarried & & 7 & $10.0 \%$ & & 16 & $11.4 \%$ & & & & \\
\hline Occupation & & & & & & & 0.314 & & & \\
\hline Unemployed & & 1 & $1.4 \%$ & & 9 & $6.4 \%$ & & Ref & & \\
\hline Non-professional & & 66 & $94.3 \%$ & & 126 & $90.0 \%$ & & 4.71 & 0.59 & 38.01 \\
\hline Professional & & 3 & $4.3 \%$ & & 5 & $3.6 \%$ & & 5.40 & 0.44 & 66.67 \\
\hline Residence & & & & & & & 0.036 & 1.91 & 1.04 & 3.51 \\
\hline Rural & & 49 & $70.0 \%$ & & 77 & $55.0 \%$ & & & & \\
\hline Urban & & 21 & $30.0 \%$ & & 63 & $45.0 \%$ & & & & \\
\hline House ownership & & & & & & & 0.120 & 1.94 & 0.83 & 4.51 \\
\hline Yes & & 62 & $88.6 \%$ & & 112 & $80.0 \%$ & & & & \\
\hline No & & 8 & $11.4 \%$ & & 28 & $20.0 \%$ & & & & \\
\hline
\end{tabular}

$C I=$ confidence interval; Freq = frequency; $O R=$ odds ratio; $R$ ef = reference; $S D=$ standard deviation . 
controls regarding educational status, marital status, occupation and house ownership. Those who lived in rural area had 2 times greater odds of having gastric cancer.

There were no significant associations between tobacco smoking, duration of smoking, and number of cigarette packs per day and the occurrence of gastric cancer. The odds of gastric cancer were 3 times higher among those who chewed tobacco than non-chewers but there was no significant association with the duration of chewing tobacco. There were nonsignificant associations between cases and controls regarding chewing khat, years and hours of chewing khat, past history of peptic ulcer, and family history of gastric or other cancer. The main source of drinking water was untreated in $87.1 \%$ of the cases and in $70.0 \%$ of the controls and those who drank untreated water had 3 times greater odds of gastric cancer (Table 2).

Regarding dietary habits, the following foods had a significant inverse association with gastric cancer: chicken, dairy products such as cheese and milk, vegetables such as sauced or cooked potatoes, cucumber, carrots, leeks, sweet pepper, fruit drinks, legumes such as beans, peas and lentils, and olive oil (Table 3).

In multiple logistic regression analysis, people who chewed tobacco had 4.4 times greater odds of having gastric cancer. Frequent consumption of chicken, sauced or cooked potatoes and fruit drinks was significantly associated with a decrease in the OR $(95 \% \mathrm{CI})$ of gastric cancer: [0.08 (0.03-0.22), $0.19(0.05-0.68)$ and $0.26(0.09-0.76)$, respectively]. Frequent consumption of white bread was significantly associated with a twofold increase in the odds of gastric cancer (Table 4).

\section{Discussion}

Living in a rural area, chewing tobacco, drinking untreated water, and frequent consumption of white bread were associated significantly with the odds of having gastric cancer.

Our study showed that people who lived in rural areas had greater odds of having gastric cancer. This was contrary to other studies that reported no significant association between residence and gastric cancer $(13,14)$. The possible explanation for this may be that in a country such as Yemen, access to healthcare facilities is limited in rural areas.

Chewing tobacco (shamma) was an important risk factor for gastric cancer in the present study. This could have been because the contents of shamma were swallowed during chewing, thus entering the stomach. In a previous study in Yemen, $H$. pylori infection was strongly associated with the habit of chewing tobacco and $H$. pylori infection is an important risk factor for gastric cancer (15). Although we reported that tobacco smoking had no significant relationship with gastric cancer, which was similar to another study (16), most other studies revealed a significantly increased risk of gastric cancer with smoking $(13,17)$. The risk increases significantly with the quantity and duration of smoking $(18,19)$. Regarding khat chewing, our study showed a nonsignificant association with gastric cancer. This could have been because of the high prevalence of khat chewing among the cases and controls. Although no previous studies have explored the association between gastric cancer and khat chewing, some have shed light on this association. One such study reported that the high tannin content of khat leaves thickens the oesophageal and gastric mucosa, which possibly causes oesophageal and gastric carcinoma. The authors found an increase in cancer of the cardia and gastro-oesophageal junction in individuals who chewed khat and smoked water pipes, but the sample size was insufficient to identify the effects of the two factors (20).

Some studies have revealed a nonsignificant association between family history of cancer and gastric cancer, which is similar to our study (13, 21). Other studies have shown that people with a positive family history of gastric cancer had greater odds of having cancer, thus reflecting the importance of hereditary and environmental factors in the occurrence of gastric cancer (4, 22-25).

Drinking untreated water was a significant risk factor for gastric cancer, which could have been because of higher levels of nitrates in untreated water (18).

Our study revealed that frequent consumption of vegetables such as starchy vegetables, cucumber, carrots, leeks, sweet pepper, and fruit drinks appeared to be protective factors against gastric cancer. Fruits and vegetables are rich sources of dietary fibre, minerals, and antioxidants such as ascorbic acid, which may inhibit initiation or progression of cancer (25). The majority of epidemiological studies in gastric cancer have reported similar results (13, $16,18,19,21,22,24,26,27)$. However, in another study, potatoes were a significant risk factor (13). In a large cohort in the United States of America, no associations were found between fruit and vegetable intake and gastric cancer risk (28). Although previous studies have reported the protective role of allium vegetables (garlic and onion) in gastric cancer $(5,24,26)$, we did not find such a relationship.

Our study showed that frequent consumption of legumes such as beans, peas and lentils had a protective effect against gastric cancer. These soya products contain considerable amounts of saponins and isoflavones, which have been shown to possess anticarcinogenic effects (5). These results are similar to many previous studies $(13,21,24)$.

We found that consumption of white bread was significantly associated with increased odds of gastric cancer. Bread is one of the essential sources of salt worldwide and its salt content can 


\begin{tabular}{|c|c|c|c|c|c|c|c|c|}
\hline \multirow[t]{2}{*}{ Variable } & \multicolumn{2}{|c|}{$\begin{array}{c}\text { Cases } \\
(n=70)\end{array}$} & \multicolumn{2}{|c|}{$\begin{array}{l}\text { Controls } \\
(n=140)\end{array}$} & \multirow[t]{2}{*}{$P$ value } & \multirow[t]{2}{*}{ OR } & \multicolumn{2}{|c|}{$95 \% \mathrm{Cl}$} \\
\hline & Freq & $\%$ & Freq & $\%$ & & & Lower & Upper \\
\hline Smoking & & & & & 0.063 & 1.74 & 0.97 & 3.11 \\
\hline Yes & 43 & $61.4 \%$ & 67 & $47.9 \%$ & & & & \\
\hline No & 27 & $38.6 \%$ & 73 & $52.1 \%$ & & & & \\
\hline Duration of smoking (yr) & & & & & 0.650 & 1.20 & 0.55 & 2.59 \\
\hline$>20$ & 25 & $58.1 \%$ & 36 & $53.7 \%$ & & & & \\
\hline$\leq 20$ & 18 & $41.9 \%$ & 31 & $46.3 \%$ & & & & \\
\hline No. of cigarettes (packs/day) & & & & & 0.523 & 1.42 & 0.49 & 4.14 \\
\hline$\geq 1$ & 7 & $24.1 \%$ & 11 & $18.3 \%$ & & & & \\
\hline$<1$ & 22 & $75.9 \%$ & 49 & $81.7 \%$ & & & & \\
\hline Tobacco chewing (shamma) & & & & & $<0.001$ & 3.35 & 1.71 & 6.55 \\
\hline Yes & 26 & $37.1 \%$ & 21 & $15.0 \%$ & & & & \\
\hline No & 44 & $62.9 \%$ & 119 & $85.0 \%$ & & & & \\
\hline Years of tobacco chewing & & & & & 0.626 & 1.33 & 0.42 & 4.24 \\
\hline$>20$ & 13 & $50.0 \%$ & 9 & $42.9 \%$ & & & & \\
\hline$\leq 20$ & 13 & $50.0 \%$ & 12 & $57.1 \%$ & & & & \\
\hline Khat chewing history & & & & & 0.069 & 1.85 & 0.95 & 3.62 \\
\hline Yes & 55 & $78.6 \%$ & 93 & $66.4 \%$ & & & & \\
\hline No & 15 & $21.4 \%$ & 47 & $33.6 \%$ & & & & \\
\hline Years of khat chewing & & & & & 0.478 & 0.69 & 0.31 & 1.49 \\
\hline$>20$ & 41 & $74.5 \%$ & 74 & $79.6 \%$ & & & & \\
\hline$\leq 20$ & 14 & $25.5 \%$ & 19 & $20.4 \%$ & & & & \\
\hline Duration of chewing khat h/session & & & & & 0.493 & & & \\
\hline $1-3$ & 20 & $36.4 \%$ & 28 & $30.1 \%$ & & Ref & & \\
\hline $4-6$ & 29 & $52.7 \%$ & 58 & $62.4 \%$ & & 0.70 & 0.34 & 1.45 \\
\hline$>6$ & 6 & $10.9 \%$ & 7 & $7.5 \%$ & & 1.20 & 0.35 & 4.11 \\
\hline Frequency of chewing & & & & & & & & \\
\hline Frequent & 54 & $77.1 \%$ & 92 & $65.7 \%$ & 0.090 & 1.76 & 0.91 & 3.40 \\
\hline Never or infrequent & 16 & $22.9 \%$ & 48 & $34.3 \%$ & & & & \\
\hline Past history of peptic ulcer & & & & & 0.363 & 1.31 & 0.73 & 2.37 \\
\hline Yes & 29 & $41.4 \%$ & 49 & $35.0 \%$ & & & & \\
\hline No & 41 & $58.6 \%$ & 91 & $65.0 \%$ & & & & \\
\hline Family history of gastric cancer & & & & & 0.071 & 4.28 & 1.04 & 17.66 \\
\hline Yes & 6 & $8.6 \%$ & 3 & $2.1 \%$ & & & & \\
\hline No & 64 & $91.4 \%$ & 137 & $97.9 \%$ & & & & \\
\hline Degree of relative & & & & & 0.333 & NA & & \\
\hline 1st & 6 & $100.0 \%$ & 2 & $66.7 \%$ & & & & \\
\hline 2nd & 0 & $0.0 \%$ & 1 & $33.3 \%$ & & & & \\
\hline Family history of other cancer & & & & & 0.688 & 1.17 & 0.54 & 2.55 \\
\hline Yes & 12 & $17.1 \%$ & 21 & $15.0 \%$ & & & & \\
\hline No & 58 & $82.9 \%$ & 119 & $85.0 \%$ & & & & \\
\hline Source of drinking water & & & & & 0.006 & 2.90 & 1.32 & 6.39 \\
\hline Untreated & 61 & $87.1 \%$ & 98 & $70.0 \%$ & & & & \\
\hline Treated & 9 & $12.9 \%$ & 42 & $30.0 \%$ & & & & \\
\hline
\end{tabular}

$C I=$ confidence interval; Freq = frequency; $N A=$ not applicable; $O R=$ odds ratio; $R e f=$ reference. 


\begin{tabular}{|c|c|c|c|c|c|c|c|c|}
\hline \multirow[t]{2}{*}{ Food } & \multicolumn{2}{|c|}{ Cases } & \multicolumn{2}{|c|}{ Controls } & \multirow[t]{2}{*}{$P$ value } & \multirow[t]{2}{*}{ OR } & \multicolumn{2}{|c|}{$95 \% \mathrm{Cl}$} \\
\hline & Freq $^{a}$ & $\%$ & Freq & $\%$ & & & Lower & Upper \\
\hline Corn & 43 & $61.4 \%$ & 82 & $58.6 \%$ & 0.691 & 1.13 & 0.63 & 2.03 \\
\hline Barley & 15 & $21.4 \%$ & 28 & $20.0 \%$ & 0.809 & 1.09 & 0.54 & 2.21 \\
\hline Stored grains & 19 & $27.1 \%$ & 36 & $25.7 \%$ & 0.824 & 1.08 & 0.56 & 2.06 \\
\hline Cooked red meat & 31 & $44.3 \%$ & 69 & $49.3 \%$ & 0.494 & 0.82 & 0.46 & 1.46 \\
\hline Chicken & 7 & $10.0 \%$ & 61 & $43.6 \%$ & $<0.001$ & 0.14 & 0.06 & 0.34 \\
\hline Sauced fish & 10 & $14.3 \%$ & 21 & $15.0 \%$ & 0.891 & 0.94 & 0.42 & 2.13 \\
\hline Grilled fish & 11 & $15.7 \%$ & 16 & $11.4 \%$ & 0.384 & 1.44 & 0.63 & 3.31 \\
\hline Cheese & 21 & $30.0 \%$ & 79 & $56.4 \%$ & $<0.001$ & 0.33 & 0.18 & 0.61 \\
\hline Milk & 46 & $65.7 \%$ & 110 & $78.6 \%$ & 0.046 & 0.52 & 0.28 & 0.99 \\
\hline Yogurt & 62 & $88.6 \%$ & 126 & $90.0 \%$ & 0.750 & 0.86 & 0.34 & 2.16 \\
\hline Sauced or cooked potatoes & 58 & $82.9 \%$ & 134 & $95.7 \%$ & 0.003 & 0.22 & 0.08 & 0.60 \\
\hline Fried potatoes & 17 & $24.3 \%$ & 51 & $36.4 \%$ & 0.078 & 0.56 & 0.29 & 1.07 \\
\hline White bread & 44 & $62.9 \%$ & 68 & $48.6 \%$ & 0.052 & 1.79 & 1.00 & 3.22 \\
\hline Macaroni & 23 & $32.9 \%$ & 57 & $40.7 \%$ & 0.270 & 0.71 & 0.39 & 1.30 \\
\hline Mandarin & 11 & $15.7 \%$ & 24 & $17.1 \%$ & 0.793 & 0.90 & 0.41 & 1.96 \\
\hline Orange & 15 & $21.4 \%$ & 48 & $34.3 \%$ & 0.057 & 0.52 & 0.27 & 1.02 \\
\hline Lemon & 31 & $44.3 \%$ & 55 & $39.3 \%$ & 0.488 & 1.23 & 0.69 & 2.20 \\
\hline Banana & 41 & $58.6 \%$ & 70 & $50.0 \%$ & 0.242 & 1.41 & 0.79 & 2.52 \\
\hline Apple & 16 & $22.9 \%$ & 46 & $32.9 \%$ & 0.136 & 0.61 & 0.31 & 1.17 \\
\hline Pomegranate & 12 & $17.1 \%$ & 23 & $16.4 \%$ & 0.896 & 1.05 & 0.49 & 2.26 \\
\hline Guava & 7 & $10.0 \%$ & 24 & $17.1 \%$ & 0.174 & 0.54 & 0.22 & 1.32 \\
\hline Grape & 21 & $30.0 \%$ & 49 & $35.0 \%$ & 0.469 & 0.80 & 0.43 & 1.48 \\
\hline Fruit drink & 8 & $11.4 \%$ & 34 & $24.3 \%$ & 0.032 & 0.40 & 0.18 & 0.92 \\
\hline Garlic & 41 & $58.6 \%$ & 90 & $64.3 \%$ & 0.421 & 0.79 & 0.44 & 1.41 \\
\hline Onion & 42 & $60.0 \%$ & 95 & $67.9 \%$ & 0.261 & 0.71 & 0.39 & 1.29 \\
\hline Cucumber & 46 & $65.7 \%$ & 111 & $79.3 \%$ & 0.034 & 0.50 & 0.26 & 0.95 \\
\hline Carrots & 44 & $62.9 \%$ & 117 & $83.6 \%$ & 0.001 & 0.33 & 0.17 & 0.64 \\
\hline Leek & 48 & $68.6 \%$ & 121 & $86.4 \%$ & 0.003 & 0.34 & 0.17 & 0.69 \\
\hline Sweet pepper & 43 & $61.4 \%$ & 105 & $75.0 \%$ & 0.044 & 0.53 & 0.29 & 0.98 \\
\hline Chilli pepper & 57 & $81.4 \%$ & 110 & $78.6 \%$ & 0.629 & 1.20 & 0.58 & 2.47 \\
\hline Beans/pea/lentil & 58 & $82.9 \%$ & 130 & $92.9 \%$ & 0.030 & 0.37 & 0.15 & 0.91 \\
\hline Almond & 2 & $2.9 \%$ & 12 & $8.6 \%$ & 0.136 & 0.31 & 0.07 & 1.44 \\
\hline Honey & 9 & $12.9 \%$ & 31 & $22.1 \%$ & 0.110 & 0.52 & 0.23 & 1.16 \\
\hline Eggs & 51 & $72.9 \%$ & 117 & $83.6 \%$ & 0.070 & 0.53 & 0.26 & 1.05 \\
\hline Olive oil & 14 & $20.0 \%$ & 49 & $35.0 \%$ & 0.027 & 0.46 & 0.24 & 0.92 \\
\hline Animal ghee & 48 & $68.6 \%$ & 81 & $57.9 \%$ & 0.134 & 1.59 & 0.87 & 2.91 \\
\hline Sweets & 46 & $65.7 \%$ & 106 & $75.7 \%$ & 0.128 & 0.61 & 0.33 & 1.15 \\
\hline Salt ${ }^{\mathrm{a}}$ & 56 & $80.0 \%$ & 98 & $70.0 \%$ & 0.125 & 1.71 & 0.86 & 3.41 \\
\hline Fahs $^{\mathrm{a}}$ & 8 & $11.4 \%$ & 31 & $22.1 \%$ & 0.064 & 0.45 & 0.20 & 1.05 \\
\hline Tea & 63 & $90.0 \%$ & 132 & $94.3 \%$ & 0.261 & 0.55 & 0.19 & 1.57 \\
\hline Coffee & 59 & $84.3 \%$ & 129 & $92.1 \%$ & 0.085 & 0.46 & 0.19 & 1.12 \\
\hline
\end{tabular}

${ }^{a}$ How many times each food item was taken. $\mathrm{Cl}=$ confidence interval; $\mathrm{OR}=$ odds ratio. 


\begin{tabular}{lccccccc}
\hline Table 4 Multivariate analysis of risk factors for gastric cancer & & & & \\
Variables & B & SE & P value & AOR & \multicolumn{2}{c}{$\mathbf{9 5 \% ~ C l}$} \\
& & & & & Lower & Upper \\
Tobacco chewing (Shamma) & 1.53 & 0.42 & $<0.001$ & 4.37 & 1.92 & 9.95 \\
Family history of gastric cancer & 1.68 & 0.85 & 0.064 & 4.81 & 0.91 & 25.28 \\
Chicken & -2.52 & 0.50 & $<0.001$ & 0.08 & 0.03 & 0.22 \\
Sauced or cooked potatoes & -1.66 & 0.66 & 0.011 & 0.19 & 0.05 & 0.68 \\
White bread & 1.03 & 0.36 & 0.015 & 2.38 & 1.18 & 4.78 \\
Salta & 0.91 & 0.42 & 0.052 & 2.27 & 0.99 & 5.21 \\
Fruit drink & -1.23 & 0.56 & 0.014 & 0.26 & 0.09 & 0.76 \\
\hline
\end{tabular}

$A O R=$ adjusted odds ratio $; C l=$ confidence interval $; S E=$ standard error.

range from 0.4 to $1.6 \mathrm{~g}$ per $100 \mathrm{~g}$ (2931). High salt intake is associated with H. pylori infection and is a promoter of gastric mucosal damage, hypergastrinaemia and cell proliferation (32). This result is consistent with another study in Uruguay (13). In our study, intake of dairy products had an inverse significant association with gastric cancer, which is supported by other studies (26, 33). Nevertheless, these findings are contrary to other studies in the Islamic Republic of Iran $(14,24)$, and another study showed that dairy products had no significant association with gastric cancer (13).
The strength of this study was the comprehensiveness of the factors studied. Besides, the numbers of cases and controls were adequate for the statistical power. However, the lack of important information on H.pylori infection could limit the overall results.

In conclusion, the important risk factors found in this study are modifiable, therefore, some recommendations can be made to prevent gastric cancer. The importance of health education and increased awareness of tobacco chewing and risky dietary behaviour should be emphasized. Political action is needed to curb tobacco consumption and improve water supply management.
Further studies are needed to clarify the effect of dietary factors and khat chewing on gastric cancer and the mechanisms involved in these processes, and to improve food selection and cooking methods to prevent gastric cancer.

\section{Acknowledgements}

The authors would like to acknowledge the invaluable help given by data collectors, all workers in the National Oncology Centre, Sana'a City and all the patients who participated in this study.

\section{Funding: None.}

Competing interests: None declared.

\section{References}

1. International Agency for Research on Cancer. GLOBACAN cancer fact sheets: stomach cancer: estimated incidence, mortality and prevalence worldwide in 2012 (http://globocan. iarc.fr/old/FactSheets/cancers/stomach-new.asp, accessed 5 October 2016).

2. Jemal A, Bray F, Center MM, Ferlay J, Ward E, Forman D. Global cancer statistics. CA Cancer J Clin. 2011 Mar-Apr;61(2):69-90. PMID:21296855.

3. Garcia M, Jemal A. Global cancer facts and figures. 2nd ed. Atlanta: American Cancer Society; 2011 (http://oralcancerfoundation.org/wp-content/uploads/2016/03/acspc-027766. pdf, accessed 5 October 2016).

4. Compare D, Rocco A, Nardone G. Risk factors in gastric cancer. Eur Rev Med Pharmacol Sci. 2010 Apr;14(4):302-8. PMID:20496539.

5. Al-Mahrouqi $\mathrm{H}$. The epidemiology of stomach cancer in Oman [thesis]. University of Otago; 2010.

6. Wani I, Parray FQ, Wani RA, Naqash SH, Wani, KA, Malik $A A$, et al. Noon Chai and gastric cancer. Int J Case Rep Images. 2013;4(3):138-42 (http://www.ijcasereportsandimages. com/archive/2013/003-2013-ijcri/001-03-2013-wani/ijcri00103201311-wani-full-text.php).
7. Rocco A, Nardone G. Diet, H pylori infection and gastric cancer: evidence and controversies. World J Gastroenterol. 2007 Jun 7;13(21):2901-12. PMID:17589938.

8. Ghouth A, \& Bafageer S. (2006). The pattern and distribution of malignancies reported in Hadramout, Yemen - 2006. J Pak Med Assoc. 2009 Nov;59(11):774-8. PMID:20361678.

9. Al-Mugahed L. Khat chewing in Yemen: turning over a new leaf. Bull World Health Organ. 2008 Oct;86(10):741-2. PMID:18949206.

10. Al-Motarreb A, Al-Habori M, Broadley KJ. Khat chewing, cardiovascular diseases and other internal medical problems: the current situation and directions for future research. J Ethnopharmacol. 2010 Dec 1;132(3):540-8. PMID:20621179.

11. Hassan NA, Gunaid AA, Murray-Lyon IM. Khat (Catha edulis): health aspects of khat chewing. East Mediterr Health J. 2007 May-Jun ;13(3) :706-18. PMID:17687845.

12. Giles C, Ireland P. Dietary questionnaire for epidemiological studies (version 2). Melbourne: Cancer Council Victoria; 1996.

13. De Stefani E, Correa P, Boffetta $\mathrm{P}$, Deneo-Pellegrini H, Ronco $\mathrm{AL}$, Mendilaharsu M. Dietary patterns and risk of gastric cancer: a case-control study in Uruguay. Gastric Cancer. 2004;7(4):211-20. PMID:15616769. 
14. Zamani N, Hajifaraji M, Fazel-tabar Malekshah A, Keshtkar AA Esmaillzadeh A, Malekzadeh R. A case-control study of the relationship between gastric cancer and meat consumption in Iran. Arch Iran Med. 2013 Jun;16(6):324-9. PMID:23725064.

15. Pandey A, Tripathi SC, Mahata S, Vishnoi K, Shukla S, Misra SP, et al. Carcinogenic Helicobacter pylori in gastric pre-cancer and cancer lesions: association with tobacco-chewing. World J Gastroenterol. 2014 Jun 14;20(22):6860-8. PMID:24944476.

16. Qiu JL, Chen K, Zheng JN, Wang JY, Zhang LJ, Sui LM. Nutritional factors and gastric cancer in Zhoushan Islands, China. World J Gastroenterol. 2005 Jul 28;11(28):4311-6. PMID:16038026.

17. Zhang Z, Zhang X. Salt taste preference, sodium intake and gastric cancer in China. Asian Pac J Cancer Prev. 2011;12(5):120710. PMID:21875268.

18. Icli F, Akbulut H, Yalcin B, Ozdemir F, Isıkdogan A, Hayran M, et al. Education, economic status and other risk factors in gastric cancer: "a case-control study of Turkish Oncology Group". Med Oncol. 2011 Mar;28(1):112-20. PMID:20054718.

19. Yassibaş E, Arslan P, Yalçin S. Evaluation of dietary and lifestyle habits of patients with gastric cancer: a case-control study in Turkey. Asian Pac J Cancer Prev. 2012;13(5):2291-7. PMID:22901209.

20. Gunaid AA, Sumairi AA, Shidrawi RG, al-Hanaki A, al-Haimi $M$, al-Absi S, et al. Oesophageal and gastric carcinoma in the Republic of Yemen. Br J Cancer. 1995 Feb;71(2):409-10. PMID:7841062.

21. Nemati A, Mahdavi R, Naghizadeh Baghi A. Case-control study of dietary pattern and other risk factors for gastric cancer. Health Promot Perspect. 201207 01;2(1):20-7. PMID:24688914.

22. Palli D, Russo A, Decarli A. Dietary patterns, nutrient intake and gastric cancer in a high-risk area of Italy. Cancer Causes Control. 2001 Feb;12(2):163-72. PMID:11246845.

23. Epplein M, Nomura AM, Hankin JH, Blaser MJ, Perez-Perez G, Stemmermann GN, et al. Association of Helicobacter pylori infection and diet on the risk of gastric cancer: a case-control study in Hawaii. Cancer Causes Control. 2008 Oct;19(8):86977. PMID:18369531.

24. Pourfarzi F, Whelan A, Kaldor J, Malekzadeh R. The role of diet and other environmental factors in the causation of gastric cancer in Iran-a population based study. Int J Cancer. 2009 Oct 15;125(8):1953-60. PMID:19569234.
25. Kumar RK, Raj SS, Shankar EM, Ganapathy EE, Abdul S, Farooq SM. Gastric carcinoma: a review on epidemiology, current surgical and chemotherapeutic options. In: Lazar D, editor. Gastric carcinoma - new insights into current management. InTech; 2013 (http://www.intechopen.com/books/ gastric-carcinoma-new-insights-into-current-management/ gastric-carcinoma-a-review-on-epidemiology-current-surgical-and-chemotherapeutic-options).

26. Pakseresht M, Forman D, Malekzadeh R, Yazdanbod A, West RM, Greenwood DC, et al. Dietary habits and gastric cancer risk in north-west Iran. Cancer Causes Control. 2011 May;22(5):725-36. PMID:21347819.

27. Phukan RK, Narain K, Zomawia E, Hazarika NC, Mahanta J. Dietary habits and stomach cancer in Mizoram, India. J Gastroenterol. 2006 May;41(5):418-24. PMID:16799882.

28. Freedman ND, Subar AF, HollenbeckAR, Leitzmann MF, Schatzkin A, Abnet CC. Fruit and vegetable intake and gastric cancer risk in a large United States prospective cohort study. Cancer Causes Control. 2008 Jun;19(5):459-67. PMID:18166992.

29. Brinsden HC, He FJ, Jenner KH, Macgregor GA. Surveys of the salt content in UK bread: progress made and further reductions possible. BMJ Open. 2013 Jun 20;3(6):e002936. PMID:23794567.

30. Dunford EK, Eyles H, Mhurchu CN, Webster JL, Neal BC. Changes in the sodium content of bread in Australia and New Zealand between 2007 and 2010: implications for policy. Med J Aust. 2011 Sep 19;195(6):346-9. PMID:21929500.

31. Ferrante D, Apro N, Ferreira V, Virgolini M, Aguilar V, Sosa $M$, et al. Feasibility of salt reduction in processed foods in Argentina. Rev Panam Salud Publica. 2011 Feb;29(2):69-75. PMID:21437363.

32. D’Elia L, Rossi G, Ippolito R, Cappuccio FP, Strazzullo P. Habitual salt intake and risk of gastric cancer: a meta-analysis of prospective studies. Clin Nutr. 2012 Aug;31(4):489-98. PMID:22296873.

33. Kim HJ, Chang WK, Kim MK, Lee SS, Choi BY. Dietary factors and gastric cancer in Korea: a case-control study. Int J Cancer. 2002 Feb 1;97(4):531-5. PMID:11802218. 